\title{
Aplicação do CF@R e de Cenários de Stress no Gerenciamento de Riscos Corporativos
}

\author{
Flávia Vital Januzzi \\ Mestre em Administração (CEPEAD/UFMG) Faculdade de Ciências Econômicas \\ Centro de Pós-Graduação e Pesquisas em Administração \\ Endereço para contato: Rua Itambacuri, n 65, apt. 202 - Carlos Prattes - Belo Horizonte - MG \\ CEP: 30710-480 - E-mail: flaviavital@des.cefetmg.br
}

\section{Fernanda Finotti Cordeiro Perobelli}

Professora (UFJF) - Faculdade de Economia - Programa de Pós-Graduação em Economia Aplicada Endereço para contato: Rua Ivon José Curi, B23 - Portal da Torre - São Pedro - Juiz de Fora Minas Gerais - CEP 36037-467 - E-mail: fernandafinotti.perobelli@ufjf.edu.br

\section{Aureliano Angel Bressan}

Professor (CEPEAD/UFMG) - Faculdade de Ciências Econômicas - Centro de Pós-Graduação e Pesquisas em Administração - Endereço para contato: Av. Antônio Carlos, 6627 - Belo Horizonte MG - CEP: 31270-901 - E-mail: aureliano@ufmg.br

Recebido em 14 de setembro de 2011. Aceito em 09 de maio de 2012.

\section{Resumo}

O presente estudo compara dois métodos para estimação do fluxo de caixa em risco (CF@R), a saber: o modelo autorregressivo integrado com médias móveis (ARIMA) e o método de vetores autorregressivos com mecanismo de correção de erros (VAR/VECM) com variáveis exógenas, ambos aplicados ao contexto do setor elétrico brasileiro. O artigo contribui com a literatura existente pela aplicação de dois métodos com o objetivo de escolher as melhores estimativas de CF@R, objetivando melhorar o gerenciamento dos riscos corporativos: o backtesting das estimativas de fluxo de caixa em risco e a geração de cenários de stress, ambos usando simulação de Monte Carlo. A última técnica averiguou os impactos de cenários extremos (obtidos a partir da distribuição dos fatores de risco), tais como o racionamento de energia, sobre a estimativa futura do fluxo de caixa operacional.

\section{Palavras-Chave}

fluxo de caixa em risco, modelagens ARIMA e VAR/VECM, simulação de Monte Carlo, backtesting, teste de stress

\section{Classificação JEL}

\section{G32}

\section{Abstract}

The present study compares two estimation approaches to cash flow-at-risk (CF@R): Autoregressive Moving Average Model (ARIMA) and Vector Autoregressive Model (VAR/ 
VECM) with exogenous variables. Both are used to calculate the cashflow-at-risk of Brazilian energy companies. Its major contribution, however, is the application of two methods used to compare CF@AR estimations, aiming to improve the managing of corporative risks: backtesting of CF@R estimates and stressed scenarios, both using Monte Carlo Simulation. The last one considered the impact of extreme values (obtained from the distribution of the risk factors), like energy rationing, over estimation of operational cash flows.

\section{Keywords}

cash flow-at-risk, ARIMA and VAR/VECM modeling, Monte Carlo Simulation, backtesting, stress test

\section{Introdução}

O Long Run Technical Document, proposto pelo Riskmetrics Group (1999), destaca que, enquanto as instituições financeiras estão focadas na gestão de seus ativos e passivos (asset-liability management), as firmas não financeiras avaliam o nível, o crescimento e a volatilidade de seus resultados operacionais, pautando-se no lucro e no fluxo de caixa gerados como fornecedores de informação relevante ao mercado. Outra distinção fundamental entre firmas e instituições financeiras reside no horizonte de análise. Comparadas aos bancos, que ativamente priorizam posições de risco de curto prazo, as firmas são menos sensíveis a flutuações diárias de seus preços de mercado, estando focadas na volatilidade mensal e trimestral de seus resultados operacionais.

Tais diferenças levaram ao desenvolvimento de uma medida de risco para o ambiente corporativo: o fluxo de caixa em risco ou CF@R, que busca mensurar o valor em risco a um determinado nível de confiança (ou a probabilidade da firma atingir certo nível de fluxo de caixa numa data futura que inviabilize o pagamento de seus compromissos operacionais ou dificulte seus planos de investimento), dadas mudanças em fatores de risco relevantes para certo período de tempo (Riskcontrol, 2002). Perobelli (2004) aponta que, dentre as vantagens advindas da implantação de sistemas de medição e de gerenciamento no âmbito das instituições não financeiras, destacamse: i) o controle dos fluxos de caixa necessários ao cumprimento dos compromissos assumidos pela firma, que incluem o pagamento de fornecedores, despesas operacionais e financeiras, amortização de empréstimos e dos investimentos programados; ii) a redução da 
volatilidade desses fluxos e, consequentemente, da probabilidade da firma deixar de honrar compromissos futuros. Podem ainda ser citados como benefícios adicionais o aumento da transparência aos investidores e a rápida assimilação de novas fontes de riscos de mercado pelos gestores. Nesse sentido, alguns autores defendem a utilização do CF@R como um importante instrumento de gestão dos riscos corporativos (Kimball, 2000; Nawrocki, 1999).

La Rocque et al. (2003) destacam ser muito comum o fato de modelos de previsão estimarem um único cenário básico ou alguns poucos cenários alternativos, dificultando, frequentemente, a inferência sobre cenários extremos, fundamentais para a gerência de risco. Em contrapartida, a distribuição de probabilidade do conjunto de cenários possíveis permite uma apuração quantitativa da incerteza e possibilita planejamentos financeiros mais embasados.

Dado o exposto, o presente estudo tem como objetivo secundário estimar o fluxo de caixa em risco, doravante denominado CF@R, para algumas das principais distribuidoras de energia do setor elétrico brasileiro, via emprego de duas abordagens, a saber: modelos autorregressivos integrados com médias móveis (ARIMA), propostos por Box e Jenkins (1970) e descritos em Makridakis, Wheelwright, e Hyndman (1998), Montgomery e Johnson (1976) e Enders (2004); e VAR/VECM (vetores autorregressivos com mecanismo de correção de erros), propostos por Sims (1980) e descritos em Maddala (2003), Heij et al. (2004) e Brooks (2008). Como objetivo principal, dois tipos de análise serão aplicados para avaliar a acurácia dos métodos: a primeira pautada na comparação dos resultados reais com os projetados (para 8 trimestres deixados fora da amostra de estimação) e a segunda embasada na análise de backtesting, ${ }^{1}$ realizada via simulação de Monte Carlo, conforme preconizada por Rubstein (1981), Sobol (1994), Ross (2002) e Winstown (2004). Em seguida, serão gerados cenários de stress, como discutido por Christoffersen (2003), para os fatores de risco, a fim de avaliar o impacto de eventos extremos sobre as projeções para o fluxo de caixa operacional. A verificação da eficácia do método empregado via procedimentos de backtesting por simulação e a sensibilização das estatísticas por testes de stress são as principais contribuições do artigo em relação a trabalhos correlatos já desenvolvidos para o mercado brasileiro (La

1 O procedimento de backtesting é aplicado apenas para a abordagem de maior acurácia preditiva fora da amostra. 
Rocque et al., 2003; Perobelli, 2004; Neto, 2007; Perobelli, Januzzi, Berbert, Medeiros, 2007; Rocha, 2008).

\section{Referencial Teórico}

O risco de mercado é descrito por Jorion (1997) como uma medida de incerteza em relação aos retornos esperados de um investimento, proveniente de oscilações nos chamados fatores de mercado, tais como taxas de juros, taxa de câmbio, preços de commodities e índices de mercado. Com um cenário de volatilidade crescente, muitas firmas não financeiras empenharam-se em mensurar sua exposição aos principais fatores de risco de mercado, gerando o desenvolvimento de uma nova medida de risco para o ambiente corporativo: o fluxo de caixa em risco (CF@R). Essa ferramenta mensura a probabilidade da firma atingir certo nível de fluxo de caixa que inviabilize o pagamento de seus compromissos operacionais e financeiros ou dificulte seus planos de investimento, dadas as mudanças nos fatores de risco para certo período de tempo (Riskcontrol, 2002).

La Rocque e Lowenkron (2004) definem o CF@R como o valor mínimo de um fluxo de caixa em uma data específica futura (T), a um nível de significância de $\alpha \%$, avaliado conforme as informações disponíveis hoje. Matematicamente, o CF@R para a data T, analisado em $t$ a (1- $\alpha \%)$ de confiança pode ser assim definido:

$$
\mathrm{P}(\text { FluxodeCaixa } \leq \mathrm{CF} @ \mathrm{R})=\alpha \%
$$

Andrén, Jankesgard e Oxlheim (2005) classificam o CF@R como uma medida pertencente à família do downside risk, por se concentrar na cauda extrema inferior da distribuição do fluxo de caixa, que sinaliza a probabilidade de ocorrência de certas instabilidades financeiras, tais como a ausência de fundos para iniciar ou dar continuidade aos programas de investimento ou falências decorrentes da incapacidade de geração de recursos internos. Para viabilizar a construção dessa ferramenta, é necessário definir, a princípio, a distribuição de probabilidade da variável fluxo de caixa. Para tal, serão discutidas neste tópico três abordagens de estimação, propostas respectivamente pelo RiskMetrics Group (1999), Stein et al. (2001) e Andrén, Jankesgard e Oxlheim (2005). 
O CorporateMetrics ${ }^{T M}$ Technical Document é uma publicação do banco JP Morgan que, através do RiskMetrics Group, apresentou definições e metodologias de cálculo do risco de mercado para firmas não financeiras, ao discutir um método para o cômputo da distribuição de probabilidades de resultados financeiros. Como consta no traba1ho, a mensuração do risco no ambiente corporativo é um processo complexo que pode ser segmentado essencialmente em cinco etapas: (A) especificação da medida de risco a ser calculada; (B) mapeamento de exposições; (C) geração de cenários; (D) estimação e (E) cômputo do risco. A etapa de mapeamento da exposição aos fatores de risco de mercado consiste na mensuração do impacto dessas variáveis sobre a medida financeira selecionada em (A). Esse processo é viabilizado por meio de modelos matemáticos (equações contábeis ou econométricas) que poderão expressar uma relação entre as variáveis. Como o relacionamento entre os resultados financeiros e as taxas de mercado estão sujeitos às particularidades de cada firma, o mapeamento das exposições deve ser fruto de pesquisas minuciosas sobre o contexto de cada organização. No que tange à geração de cenários para os fatores de risco de mercado, faz-se necessário, a priori, especificar as respectivas distribuições de probabilidade desses fatores para diferentes horizontes de tempo. Essas são obtidas a partir da aplicação de testes de adequação de distribuição às séries amostrais das variáveis de risco. Com base nesses resultados, são gerados $\mathrm{N}$ valores aleatórios, via Simulação de Monte Carlo, que alimentam os modelos estimados na etapa (B), viabilizando o cômputo de $\mathrm{N}$ cenários para as medidas financeiras de interesse.

Cabe salientar que não existe um consenso sobre o melhor método de previsão de longo prazo para os fatores de risco. No entanto, o RiskMetrics (1999) sugere que seja considerado mais de um modelo, levando em consideração os seguintes critérios: acurácia das distribuições para os diversos horizontes de tempo desejados, facilidade de implementação, habilidade em testar eventos extremos e capacidade de incorporar as informações correntes no mercado e captar as condições macroeconômicas. A partir da distribuição da variável financeira (fluxo de caixa, lucro ou mesmo receita) poderão ser calculadas estatísticas de risco tais como: (i) desvio padrão (representa uma medida simétrica padronizada de dispersão da variável de análise em relação à média, estando estritamente relacionada ao grau de variabilidade associada à ocorrência dos valores futuros da variável de interesse); (ii) queda máxima em relação a um valor alvo (indica a probabilidade 
da variável financeira de interesse ficar abaixo de um valor alvo em virtude dos riscos de mercado); (iii) intervalo de confiança (permite avaliar a probabilidade de ocorrência da variável de interesse dentro de um intervalo específico).

Como segunda referência relevante sobre o assunto, Stein et al. (2001) propuseram um modelo que buscava suprir um ponto crítico presente na abordagem apresentada pelo RiskMetrics Group. Segundo os autores, em firmas não financeiras a identificação de todos os fatores de risco do fluxo de caixa pode ser uma tarefa complexa, a ponto de gerar resultados de pouca acurácia caso algum fator relevante seja negligenciado, ou não captar de forma consistente possíveis relações secundárias entre os fatores de risco e o fluxo de caixa. Em virtude do exposto, os autores sugeriram a utilização de um método focado na mensuração da volatilidade total do fluxo, em detrimento da volatilidade condicionada aos riscos de mercado. Logo, a volatilidade total, segundo essa abordagem, representa a principal variável de interesse. Em virtude da insuficiência de informações capazes de viabilizar a obtenção de estimativas estatisticamente significativas para a volatilidade, foi proposto por Stein et al. (2001) o cálculo do CF@R com base na distribuição de probabilidades dos fluxos de caixa das firmas observadas diretamente e não via distribuição dos fatores de risco, como na proposta anterior. A distribuição de probabilidades neste método é construída segundo as estimativas dos erros passados. Esses subsidiam a geração dos choques aleatórios nas equações de previsão para viabilizar a simulação do $\mathrm{CF} @ \mathrm{R}$ intrínseco de cada firma. Tais choques aleatórios são selecionados de subconjuntos de resíduos formados conforme agrupamentos preestabelecidos, contendo firmas similares. O modelo apresentado por Stein et al. (2001) consiste em uma estimação empírica da distribuição de probabilidades. No entanto, sua principal limitação é a desconsideração dos fatores de risco específicos de cada firma, inviabilizando a mensuração da exposição do fluxo de caixa aos movimentos macroeconômicos e de mercado.

O terceiro método, proposto por Andrén, Jankesgard e Oxlheim (2005), tenta superar as deficiências dos anteriores por meio da criação do Exposure Based CF@R. Os autores propuseram um avanço teórico em relação ao método desenvolvido pelo RiskMetrics (1999) ao incorporar um conjunto de coeficientes de exposição (deltas) de fatores de risco (macroeconômicos e de mercado) interdependentes 
entre si, construídos com base em uma regressão multivariada, denominada pelos autores de MUST (Modeling Uncertainty Strategy). Dessa forma, uma análise multivariada do EBITDA $^{2}$ (proxy para o fluxo de caixa) pode ser conduzida utilizando mudanças aleatórias nos fatores de risco selecionados como variáveis explicativas. A seguinte representação do método MUST foi proposta:

$$
\begin{aligned}
& X_{t}^{D C}-E_{t-1}\left[X t^{D C}\right]=\beta_{0}+\beta_{1}\left(\pi_{t}{ }^{D C}-E_{t-1}\left[\pi_{t}{ }^{D C}\right]\right)+\beta_{2}\left(\pi_{t}{ }^{F C}-E_{t-1}\left[\pi_{t}{ }^{F C}\right]\right)+\beta_{3}\left(S_{t}{ }^{D C F C}-E_{t-1}\left[S_{t}{ }^{D C F C}\right]\right) \\
& +\beta_{4}\left(i_{t}{ }^{D C}-E_{t-1}\left[i_{t}{ }^{D C}\right]\right)+\beta_{5}\left(i_{t}{ }^{F C}-E_{t-1}\left[i_{t}{ }^{F C}\right]\right)+\beta_{6}\left(P_{t}{ }^{D C}-E_{t-1}\left[P_{t}{ }^{D C}\right]\right)+\varepsilon_{t}
\end{aligned}
$$

Onde:

$\mathrm{Xt}^{\mathrm{DC}}$ é o fluxo de caixa em moeda local (domestic currency ou DC) no período t, $\pi$ é a inflação, $S^{\mathrm{DC} / \mathrm{FC}}$ é a taxa de câmbio spot em moeda local por unidade de moeda estrangeira (foreign currency ou FC), $i$ é a taxa de juros e $P$ é o preço de mercado dos fatores de risco relevantes para a rentabilidade corporativa. $\mathrm{O}$ termo $\mathrm{E}_{\mathrm{t}-1}$ é o operador da expectativa no período $t-1$, enquanto $\varepsilon_{t}$ mensura a mudança no fluxo de caixa no período $t$, independente das variáveis macroeconômicas e de mercado consideradas.

Segundo os autores, os coeficientes dessa regressão permitem averiguar o impacto financeiro de variações não antecipadas dos fatores de risco (portanto, em relação a valores previstos) sobre a variável de interesse. Adicionalmente, os betas da equação também podem ser obtidos com o intuito de mensurar as mudanças no fluxo de caixa ocasionadas por fatores macroeconômicos ou de mercado e para quantificar a parcela da oscilação explicada por outros fenômenos. No primeiro caso, utiliza-se como fator de mensuração o coeficiente de determinação $\left(R^{2}\right)$. A relativa importância não macroeconômica será indicada por $\left(1-R^{2}\right)$. Essas duas fontes de variação são utilizadas concomitantemente na estimação do CF@R.

Para derivar a distribuição condicional do fluxo de caixa por esse método, deve-se obter a priori a matriz de covariância das variáveis macroeconômicas e de mercado identificadas no modelo de exposição anteriormente calculado em (2). Ressalta-se que os valores simu-

2 Cabe ressaltar que o EBITDA (Earnings Before Interest, Tax, Depreciation and Amortization) é obtido a partir de informações contábeis e, portanto, está sujeito à forma e regras contábeis brasileiras. Além disso, há diferenças entre o resultado e geração de caixa quando expressos contabilmente em relação ao resultado potencial (valor da empresa) obtido a partir de marcação a mercado. 
lados são selecionados aleatoriamente a partir dessa matriz, obtida via decomposição de Cholesky. ${ }^{3}$ Esses valores simulados, por fim, são inseridos na equação de previsão, gerando uma distribuição simulada do fluxo de caixa condicional às variáveis macroeconômicas e de mercado.

Para que seja apurada uma estimativa do fluxo de caixa total, a distribuição do fluxo de caixa condicional deverá ser completada com a distribuição do termo de erro. Caso o termo de erro seja bem comportado, ele não será correlacionado com as variáveis explicativas e tampouco com seus valores defasados, sendo possível extrair um valor da distribuição normal $\left(\mathrm{N} \sim\left[0, \sigma^{2}\right]\right)$ e adicioná-lo à distribuição condicional. No Brasil, Perobelli et al. (2007) adotaram procedimento semelhante, incorporando à análise tanto a influência dos fatores de risco macroeconômicos quanto de fatores de riscos próprios das firmas consideradas.

\section{Método Empírico Para Estimação Do Cash Flow-At-Risk}

Os trabalhos divulgados pelo RiskMetrics em 1999 partem do mapeamento da exposição do fluxo de caixa aos fatores de risco de mercado, gerando uma distribuição de média condicional. Não obstante, tanto em firmas financeiras quanto não financeiras, a identificação de todos os fatores de risco referentes ao fluxo de caixa pode ser uma tarefa complexa, a ponto de gerar resultados com pouca acurácia caso algum fator relevante seja negligenciado, ou não captar de forma consistente possíveis relações secundárias entre as variáveis analisadas.

Andrén, Jankesgard e Oxlheim (2005) propõem um modelo que agregue tanto a distribuição condicional do fluxo de caixa, quanto a não condicional, gerando a estimativa do fluxo de caixa total. Por conseguinte, o método incorpora tanto a distribuição do fluxo de caixa condicional quanto a distribuição do termo de erro (risco idiossincrático), a fim de minimizar os efeitos dos fatores de risco não especificados, dada a sua não observação, sobre os resultados da variável endógena. Metodologicamente, para a construção e validação dos modelos de gestão de riscos corporativos sob essa proposta, devem ser considerados os pontos seguintes: (A) definição das va-

3 Para uma excelente discussão sobre tal decomposição, ver Hamilton (1994). 
riáveis de estudo, subdividindo-as em variáveis dependentes (fluxo de caixa) e candidatas a variáveis independentes (fatores de risco macroeconômicos e próprios do negócio); (B) estimação de modelos econométricos para identificação dos fatores de risco; (C) simulação dos fatores de risco e do fluxo de caixa operacional em risco; (D) seleção da abordagem de maior acurácia preditiva fora da amostra; (E) backtesting e (F) stress test.

\section{A. Definição das Variáveis de Estudo}

A princípio, foram selecionadas doze firmas (com dados disponíveis a partir do $1^{\circ}$ trimestre de 1998), obtidas a partir da análise do Índice de Energia Elétrica (IEE), proposto pela Bovespa (Bolsa de Valores de São Paulo), conforme a composição apresentada em 12/02/2009. Como os índices setoriais, segundo a Bovespa (2009), têm o objetivo de oferecer uma visão segmentada do comportamento dos mercados de ações e representar uma medida do comportamento agregado do segmento econômico considerado, acredita-se que a escolha das firmas a partir do IEE pode ser considerada válida dentro do processo de determinação da amostra relevante. No entanto, face à escassez de informações referentes à série histórica dos fatores de risco próprios do negócio ${ }^{4}$ (demanda por classe de consumo, tarifa média de venda e compra de energia, entre outros), um segundo filtro foi aplicado à amostra, implicando a seleção de cinco distribuidoras que totalizavam $40,58 \%$ do mercado nacional de distribuição de energia elétrica, segundo dados da ANEEL (2008). Essas distribuidoras podem ser assim caracterizadas: i) Companhia Energética de Minas Gerais (CEMIG); ii) Centrais Elétricas de Santa Catarina (CELESC); iii) Companhia Energética do Ceará (COELCE), iv) Companhia Paranaense de Energia (COPEL); v) AES Eletropaulo (ELETROPAULO).

Para facilitar o processo de estimação dos modelos de exposição do fluxo de caixa das firmas aos fatores de risco, foram consideradas como variáveis dependentes as principais contas que compõem o fluxo de caixa operacional (FCO) das firmas, a saber: Receita Operacional Líquida (RECL); Custo dos Produtos Vendidos (CVM); Despesas Operacionais (DESPOP) e Depreciação e Amortização

\footnotetext{
${ }^{4}$ Perobelli (2004) define os fatores de risco como aquelas variáveis capazes de provocar oscilações no fluxo de caixa das firmas, podendo ser de natureza macroeconômica ou própria do negócio.
} 
(D\&A). Tais informações foram obtidas a partir da Demonstração do Resultado de Exercício, do Demonstrativo do Fluxo de Caixa e do Relatório Anual das firmas controladoras analisadas.

Os fatores de risco próprios, que constituem o primeiro conjunto de variáveis independentes, foram retirados do Comentário de Desempenho Trimestral e Press Release trimestral divulgados pelas firmas, podendo ser assim enumerados:

a) Tarifa Média de Venda de Energia Elétrica (em $\mathrm{R} \$ / \mathrm{MWh}$ ), envolvendo residência, indústria, comércio, rural, poder público e consumo próprio;

b) Reajuste Anual Tarifário realizado pela ANEEL (em \%) com o objetivo de restabelecer anualmente o poder de compra da receita obtida pela concessionária;

c) Recomposição Tarifária Extraordinária (em \%) concedida pelo Governo no $4^{\circ}$ trimestre de 2001, a fim de compensar as distribuidoras pelos efeitos financeiros negativos decorrentes do período de racionamento;

d) Tarifa Média de Venda de Energia Elétrica em reais por megawatt-hora (em R $\$ / M W h$ );

e) Mercado atendido pela firma (em MWh), englobando mercado total, residencial, industrial, comercial, rural, poder público;

f) Montante de Energia Elétrica comprada para revenda (em $\mathrm{MWh}$ ). Representa a quantidade de energia elétrica total comprada das geradoras, seja por meio de contratos iniciais (nesses, as quantidades e os valores de energia são homologados pela ANEEL) ou da energia fornecida pela Itaipu Binacional; seja por contratos bilaterais de longo ou curto prazo (referem-se às despesas com compra de energia realizadas pelas empresas de distribuição de energia elétrica, para complementar a energia necessária para atendimento de seu mercado consumidor);

g) Tarifa média de compra de energia em reais por megawatthora (em $\mathrm{R} \$ / \mathrm{MWh}$ ). Refere-se a uma média das tarifas praticadas pelas geradoras, seja por contratos iniciais, bilaterais de longo ou de curto prazo.

Ressalta-se que tais dados referem-se às demonstrações das empresas controladoras, sendo expressos em valores reais, corrigidos com base no IGPM (Índice Geral de Preços do Mercado), que constitui o 
principal indexador dos contratos negociados pelas distribuidoras do setor. Além das informações específicas de cada firma, também foram selecionadas as variáveis macroeconômicas constantes da Tabela 1 para compor o segundo conjunto de variáveis independentes:

Tabela 1- Caracterização das Variáveis Macroeconômicas

\begin{tabular}{|c|c|c|}
\hline Variável & Sigla & Fonte \\
\hline Índices de Preços ao Atacado-Eletrodomésticos & IPELETROD & Fundação Getúlio Vargas \\
\hline Salário Mínimo (em R\$) & SMNOM & Ministério do Trabalho e Emprego \\
\hline Taxa de Câmbio Comercial Venda (em R\$US\$) & PTAX & Banco Central \\
\hline PIB Indústria ( em milhões de R\$) & PIBIND & Instituto Brasileiro de Geografia \\
\hline $\begin{array}{l}\text { Produto Interno Bruto_Indústria (Eletricidade, Gás e } \\
\text { Água)(em milhões de R\$) }\end{array}$ & PIBEGA & Instituto Brasileiro de Geografia \\
\hline Índice Produto Interno Bruto a Preço de Mercado & $\mathrm{PIB}$ & Instituto Brasileiro de Geografia \\
\hline Taxa de Juros SELIC ( em \%) & SELIC & Banco CEntral \\
\hline Taxa de Demprego Aberto ( em \%) & DESEMP & $\begin{array}{l}\text { Fundação Sistema Estadual de } \\
\text { Análise de Dados }\end{array}$ \\
\hline Índice de Alta Intensidade com Gastos com Energia & ALTOGASTO & Instituto Brasileiro de Geografia \\
\hline Índice de Média Intensidade com Gastos com Energia & MÉDIOGASTO & Instituto Brasileiro de Geografia \\
\hline Índice de Baixa Intensidade com Gastos com Energia & BAIXOGASTO & Instituto Brasileiro de Geografia \\
\hline Índice de Preços do Petróleo & PETR & $\begin{array}{c}\text { Instituto de Pesqusia Econômica } \\
\text { Aplicada }\end{array}$ \\
\hline
\end{tabular}

Nota: A tabela apresenta o conjunto de variáveis analisadas e as respectivas siglas adotadas para rotulá-las na base de dados.

Fonte: Elaborado pelos autores.

As variáveis PIBIND, PIB, PIBEGA, ALTOGASTO, MÉDIOGASTO e BAIXOGASTO foram incluídas como proxies para o nível de atividade na economia. Em termos específicos, os índices de intensidade com gastos com energia quantificam a participação dos gastos na compra de energia elétrica, em relação ao valor da transformação industrial. Segundo o IBGE (2009), foram classificados como alta intensidade setores com coeficientes (dados pela razão do valor de compra de energia elétrica pelo valor de transformação industrial) superiores a 3,9\%. Entre 3,9 e 2\%, foram definidos como intensidade média; e inferiores a $2 \%$, classificados como intensidade baixa.

O IPELETROD foi utilizado para avaliar o impacto do aumento do preço de eletrodoméstico sobre o fluxo de caixa operacional das distribuidoras. A variável SELIC foi incluída a fim de se considerar a taxa de juros básica vigente na economia brasileira, que, conjugada 
à variável renda, expressa pelo salário mínimo (SMNOM), representa fator de limitação do consumo das famílias. Ressalta-se que o SMNOM também foi considerado na avaliação do impacto dos encargos com mão de obra sobre os custos operacionais das firmas.

Outras variáveis empregadas para explicar a variável Custos e Despesas Operacionais (CUSTO\&DESPOP), dizem respeito ao PTAX e ao PETR, que representam, respectivamente, o impacto da oscilação cambial sobre os custos de energia comprada, visto que todo pagamento referente à compra de energia de Itaipu é efetuado em dólar, e da oscilação do preço do combustível sobre a conta consumo combustível, o qual representa um custo não gerenciável para o setor. Tais informações foram consideradas relevantes a partir da leitura dos relatórios trimestrais das cinco firmas analisadas. A taxa de desemprego (DSEMP) foi incluída como proxy para captar possíveis efeitos de períodos de recessão econômica sobre o consumo de energia dos agentes de mercado. Adicionalmente, a fim de se averiguar relações sazonais, foram geradas variáveis dummies trimestrais.

Conforme já mencionado, a variável dependente foi representada pelo fluxo de caixa operacional. Segundo Iudícibus, Martins e Gelbcke (2007), ${ }^{5}$ as atividades operacionais envolvem todas as atividades relativas a bens e serviços e aos eventos que não sejam definidos como atividades de financiamento e de investimento. As entradas operacionais de caixa podem assim ser enumeradas: a) recebimentos pela venda de produtos e serviços à vista, ou de duplicatas correspondentes no caso de vendas a prazo, incluindo os recebimentos decorrentes dos descontos de duplicatas emitidas, e b) qualquer outro recebimento que não se origine de transações definidas como atividades de investimento e de financiamento.

As saídas operacionais de caixa podem ser assim enumeradas: a) pagamento a fornecedores referentes ao suprimento da matéria-prima para a produção ou de bens para revenda; caso a compra seja a prazo, também deve ser considerado o pagamento do principal dos títulos de curto prazo ou longo prazo a que se refere a compra; b) pagamentos aos fornecedores de outros insumos de produção, incluindo os serviços prestados a terceiros; c) pagamento aos governos Federal, Estadual e

\footnotetext{
5 O capítulo 31 da obra Manual de Contabilidade das Sociedades por Ações, publicado no ano de 2007, tem como base as orientações do FASB (Financial Accounting Standards Board) e do IASB (International Accounting Standards Board).
} 
Municipal, referentes a impostos, a multas, a taxas alfandegárias e a outros tributos e taxas (Iudícibus, Martins e Gelbcke, 2007).

Perobelli (2004) destaca que, quando se analisa o setor de energia elétrica, algumas simplificações podem ser consideradas pelo analista externo à firma para o cômputo do fluxo de caixa operacional, a saber:

1) utilização do lucro operacional do exercício (receita bruta menos deduções, menos custo do produto vendido, menos despesas operacionais), acrescido da despesa de depreciação (quando essa tiver sido previamente descontada como custo ou despesa operacional). Com isso, eliminam-se contas, não caixa (tais como resultado de equivalência patrimonial);

2) consideração dos estoques como iguais a zero (visto que estes representam uma parcela ínfima do Ativo Circulante das concessionárias de energia) e prazos médios de recebimento de clientes iguais aos prazos médios de pagamento aos fornecedores (dado que os volumes financeiros negociados a prazo não são expressivos nesse segmento). Com isso, elimina-se a necessidade de capital de giro das firmas.

Ressalta-se que, após testes empíricos, definiu-se que o fluxo de caixa operacional seria obtido indiretamente pela estimação de modelos individuais para a Receita Operacional Líquida, para os Custos \& Despesas Operacionais ${ }^{6}$ e para a Depreciação e Amortização, ${ }^{7}$ facilitando, inclusive, a identificação dos fatores de risco referentes a cada série (tal informação é perdida quando se tenta estimar um modelo único para a série já agregada de fluxo de caixa).

\section{B. Estimação de Modelos Econométricos para Identificação dos Fatores de Risco}

Antes de partir para a estimação, foram realizados testes de estacionaridade na série Receita Operacional Líquida e na série da variável agregada Custo \& Despesa Operacional. Para isso, aplicou-se o teste

${ }^{6}$ Os Custos e Despesas Operacionais foram considerados de forma agregada, a fim de corrigir problemas de descontinuidade, dado que existem períodos dentro da série histórica da maioria das empresas em que os custos foram lançados conjuntamente com as despesas operacionais.

7 Para o cálculo da depreciação, utilizou-se como critério a média dos últimos cinco anos, devido à baixa variabilidade da série histórica. 
de Phillips-Perron para identificação de raiz unitária. No entanto, a fim de evitar que os resultados fossem enviesados por quebras estruturais (representadas por eventos atípicos, tais como o reajuste tarifário ocorrido no quarto trimestre de 2001), foi adotado o procedimento discutido por Johnston e Dinardo (2001), realizando, a priori, a estimação de equações do tipo:

$$
y_{t}=a_{0}+\alpha_{1} D+\varepsilon
$$

Após modelar tais eventos não recorrentes pela inserção das dummies, o teste de Perron foi aplicado na série de resíduos, com a finalidade de averiguar as propriedades estacionárias das variáveis analisadas. A partir da estatística p-value, foi possível inferir que as séries de Receita Operacional Líquida da COPEL, COELCE e da CELESC, bem como o Custo \& Despesa Operacional da CELESC e da COPEL, não apresentaram propriedades estacionárias, dado um nível de significância de 10\%, devendo ser diferenciadas antes da estimação dos modelos econométricos. As demais séries exibiram comportamento estacionário, não sendo necessária a aplicação de nenhum procedimento algébrico antes do cômputo das equações de previsão.

As abordagens de estimação utilizadas para a identificação dos fatores de risco (ARIMA e (VAR/VECM) serão descritas separadamente nos tópicos subsequentes. Salienta-se que todos os resultados obtidos foram interpretados de acordo com um nível de significância de $10 \%$, visto que, dada a limitação de dados disponíveis $(n=47), 8$ a maioria dos coeficientes estimados não seria significativa a $5 \%$.

\section{B.1 Estimação dos Fatores de Risco Relevantes por Modelos ARIMA}

Os modelos ARIMA foram estimados por meio do software EVIEW-S®. Metodologicamente, para viabilizar a identificação das possíveis configurações dos modelos ARIMA, foram considerados os resultados do teste Q de Ljung-Box, empregado para analisar a significância dos lags presentes na função de autocorrelação e autocorrelação parcial. Tal instrumental embasou a construção das possíveis especificações econométricas para as variáveis financeiras em estudo. ${ }^{9}$ Com base na seleção da menor estatística SBIC (Schwartz

\footnotetext{
8 Para fins de backtesting, foram retiradas oito observações, gerando um total de 47 observações para estimação dos modelos econométricos.

9 Em virtude da limitação de páginas do artigo, os modelos foram suprimidos. No entanto, os
} 
Bayesian Information Criterion), foram definidos os modelos finais para a construção do CF@R. Ressalta-se, adicionalmente, que, a fim de captar os efeitos de eventos atípicos (tais como o reajuste anual extraordinário) e garantir a estabilidade dos modelos, foram adicionadas variáveis dummies, ${ }^{10}$ tomando como base os resultados do teste de Chow, descrito por Brooks (2008).

Com a intenção de validar estatisticamente tais especificações, foram verificadas as propriedades dos resíduos dos modelos estimados, ou seja, autocorrelação estatisticamente nula, homocedasticidade e normalidade. Os termos de erro de quase todas as equações estimadas para as variáveis financeiras apresentaram propriedades de séries do tipo ruído branco dado um nível de significância de 10\%. Apenas as variáveis Custo \& Despesa Operacional da CEMIG e Receita Operacional da COELCE apresentaram termos de erro não normais a um nível de significância de 10\%. Como discutido por Hamilton (1994), o método de máxima verossimilhança tenderá a gerar estimativas razoáveis para os coeficientes dos modelos tipo ARIMA, mesmo quando o termo de erro for não gaussiano. No entanto, para efetuar uma correção no erro padrão dos betas do modelo, o autor propôs a estimação por quasi máxima verossimilhança. Nesse método, computa-se a matriz variância-covariância proposta por White (1982). Ressalta-se, portanto, que, em ambos os casos mencionados, os procedimentos de correção foram devidamente aplicados.

\section{B.2 Estimaçãodos Fatores deRiscoRelevantesporModelos VAR/VECM}

Os modelos VAR/VECM foram computados por meio do software STATA®. Para a estimação dos modelos VAR/VECM, foi aplicado um procedimento stepwise, conforme sugerido por Drapper e Smith (1998). A ordem de inclusão se pautou nos resultados obtidos após o cômputo da correlação cruzada dos fatores de risco com as variáveis dependentes. Logo, os fatores de risco de maior correlação cruzada foram selecionados em detrimento dos demais. O Teste de Granger foi empregado para constatar possíveis relações de causalidade bidirecional no sentido Granger, entre as variáveis analisadas, verificando a relevância dos movimentos de uma variável na previsão

mesmos podem ser disponibilizados mediante solicitação.

10 Segundo STATA (2005), modelos do tipo ARIMA que incorporam uma combinação linear da variável dependente com outras variáveis independentes, diferentes de seus valores passados e do termo de erro defasado, podem ser denominados modelos do tipo ARMAX. 
das oscilações da outra, como discutido por Hamilton (1994). Os testes de Granger foram significativos, para um nível de significância de 10\%, para a Receita Operacional Líquida da COPEL juntamente com sua tarifa média de vendas, bem como para o Custo e Despesa Operacional da CELESC juntamente com sua tarifa média de compras.

A validação estatística dos respectivos modelos foi efetuada a partir da análise das propriedades dos resíduos dos modelos VAR/VECM, ou seja, autocorrelação estatisticamente nula, homocedasticidade e normalidade. Os termos de erro de todas as equações estimadas para as variáveis financeiras apresentaram propriedades de séries do tipo ruído branco dado um nível de significância de 10\%.

\section{Simulação dos Fatores de Risco e do Fluxo de Caixa Operacional}

A etapa $C$ envolveu o cálculo da distribuição do fluxo de caixa operacional para cada uma das distribuidoras de energia elétrica analisadas. Para tal, aplicou-se o método de simulação de Monte Carlo descrito por Sobol (1994), Mun (2006) e Winston (2004), com o auxílio do software @RISK®. Com o intuito de descrever adequadamente esse processo, são enumerados separadamente os procedimentos implementados para cada uma das abordagens econométricas utilizadas.

\section{C.1 Simulação Aplicada aos Modelos ARIMA}

A fim de viabilizar a construção de 10.000 cenários para o fluxo operacional e captar o efeito de variáveis omitidas sobre o comportamento futuro da variável de análise, simulou-se apenas o termo de erro obtido com base nos modelos ARIMA. Foram empregados, $a$ priori, testes de adequação para parametrização da distribuição dos termos de erros obtidos a partir dos modelos computados para cada variável financeira (Receita Operacional Líquida e Custos e Despesas Operacionais). A partir do sorteio de 10.000 valores aleatórios extraídos das respectivas distribuições dos resíduos, calcularam-se os parâmetros de média e desvio para a distribuição do fluxo de caixa, conforme explicitado na Tabela 2. 
Ressalta-se que, ao considerar a média da distribuição uma estimativa apropriada para o comportamento futuro do Fluxo de Caixa Operacional, por sumarizar 10.000 cenários gerados em uma única medida, a estatística obtida em $\mathrm{t}+\mathrm{l}$ representa a projeção para o comportamento da variável dependente defasada nos modelos de previsão referentes ao instante $t+2$. Por conseguinte, a média obtida em $t+2$ substituiu o valor endógeno defasado em $t+3$ e assim sucessivamente até que a distribuição em $t+8$ fosse estimada. 


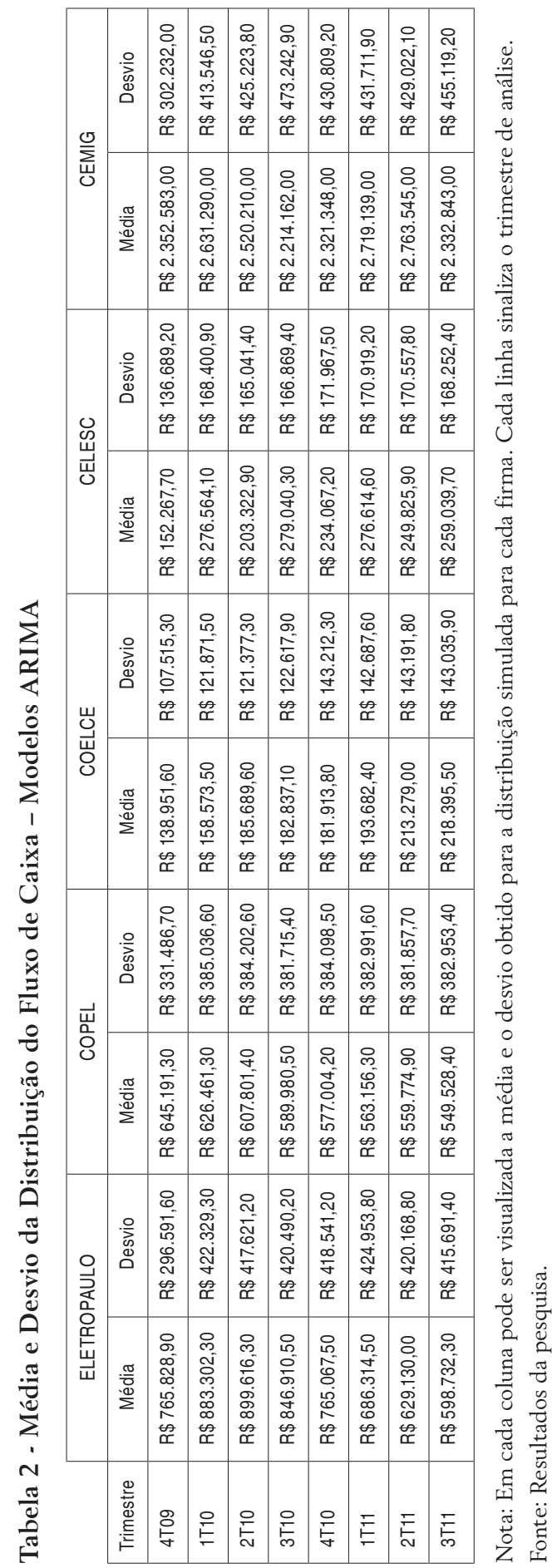




\section{C.2 Simulação Aplicada aos Modelos VAR/VECM}

Para o cálculo da distribuição do fluxo de caixa operacional em risco a partir dos modelos VAR/VECM, simulou-se a distribuição condicionada e não condicionada de forma concomitante, como proposto por Andrén, Jankesgard e Oxlheim (2005), a fim de se superar as deficiências dos trabalhos baseados em RiskMetrics (1999), principalmente no que tange ao efeito negativo de variáveis omitidas sobre a acurácia do $\mathrm{CF} @ \mathrm{R}$. Em circunstâncias nas quais os fatores de risco eram previamente conhecidos (como no caso de modelos VAR/ VECM estruturados apenas com variáveis defasadas), o CF@R para um passo à frente foi estimado via simulação de 10.000 valores para o termo de erro, selecionados aleatoriamente a partir da distribuição normal.

Para modelos VAR/VECM na qual estavam presentes fatores de risco macroeconômicos, foram realizadas adicionalmente simulações de 10.000 valores para cada um dos fatores de risco, respeitando, para fins da simulação, as relações históricas entre os fatores de risco expressas na matriz de Cholesky.

Os parâmetros das distribuições obtidas a partir dos modelos VAR/ VECM apresentaram a configuração expressa na Tabela 3: 


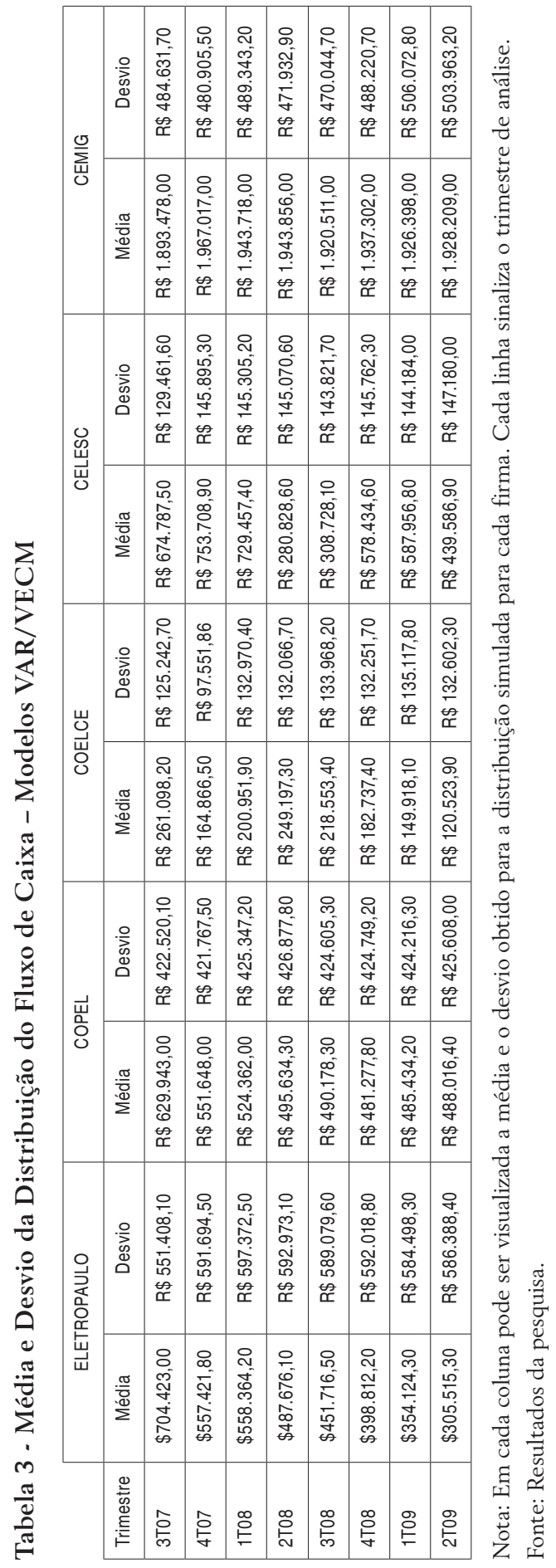


D. Comparação das Abordagens Econométricas: Modelos ARIMA versus VAR/VECM

Uma análise mais específica dos períodos de maior erro percentual, calculados com base na parte da série histórica deixada de fora da amostra de estimação, viabilizou a realização de inferências sobre a acurácia dos modelos estimados e a seleção da melhor abordagem para cômputo da medida de CF@R. A partir das informações presentes nos relatórios de desempenho e press releases divulgados pelas distribuidoras, foi possível detectar os fatores presentes no contexto de cada firma que não foram capturados pelos métodos matemáticos. As projeções fora da amostra, que englobaram o intervalo compreendido entre o $4^{\circ}$ trimestre de 2009 e o $3^{\circ}$ trimestre de 2011, estão expressas nos Gráficos 1 e 2 respectivamente. Pelo exposto nos Gráficos 1 e 2, constatou-se que os modelos estimados para a COPEL não captaram adequadamente situações de elevação ou de queda acentuada no fluxo de caixa operacional, tais como as ocorridas no $1^{\circ}$ trimestre de 2011, por exemplo. Tais eventos foram possivelmente decorrentes principalmente em função de: a) da elevação de $8,5 \%$ na conta "encargos do uso da rede elétrica"em razão, principalmente, da entrada em operação de novos ativos e do maior custo de Encargos de Serviços do Sistema (ESS), conforme definido pela ANEEL; b) acréscimo de 16,9\% na conta "energia elétrica comprada para revenda" em função do maior custo com aquisição de energia dos leilões (CCEAR) e da Câmara de Comercialização de Energia Elétrica (CCEE), parcialmente compensado pela redução nos custos com compra de energia de Itaipu. Tais fatores acabaram por contribuir para o crescimento dos custos no período.

No que tange à COELCE, foi observado que os modelos ARIMA e VAR/VECM sinalizaram para um maior erro percentual em momentos de maior volatilidade do fluxo de caixa. Durante o $4^{\circ}$ trimestre de 2009, por exemplo, a empresa destacou em seu release trimestral um crescimento da Receita Operacional Líquida de 4,8\% em decorrência do acréscimo de novos consumidores à base comercial da Companhia, na classe residencial (normal e baixa renda), e na classe rural. Esta ampliação do mercado consumidor representa o reflexo dos investimentos para conexão de novos clientes, que também foram realizados ao longo de 2010 e 2011. Tal fenômeno não foi captado pelo modelo ARIMA (que subvalorizou o resultado operacional da empresa). Ao contrário da abordagem anterior, o Modelo VAR supervalorizou o resultado operacional da empresa, apesar do 
crescimento observado no $4^{\circ}$ trimestre de 2009 de $9,1 \%$, conforme destacado pelo release do referido período. Em virtude da volatilidade presente na parte fora da amostra da CELESC, as abordagens ARIMA e VAR/VECM apresentaram baixa precisão preditiva para todos os horizontes de previsão. No primeiro horizonte de previsão, por exemplo, por subvalorizar o custo da empresa o modelo VAR acabou por gerar uma estimativa significativamente superior ao dado real. Já o modelo ARIMA não foi capaz de captar o incremento de 15\% na Receita Operacional líquida (quando comparado ao mesmo período do trimestre anterior), decorrente do incremento do crescimento no consumo de energia elétrica, devido à recuperação da economia, e da melhoria dos índices de produtividade da empresa.

Quanto aos modelos elaborados para a CEMIG, destaca-se a baixa precisão preditiva para grande parte dos horizontes de previsão. Acredita-se possivelmente que tal efeito seja decorrente do fato de, devido a eventos societários ocorridos em dezembro de 2009, a partir do $1^{\circ}$ trimestre de 2010 todos os números consolidados passaram a refletir os efeitos da participação da empresa na Light, da ordem de $13,03 \%$. No que diz respeito à ELETROPAULO, as notas informativas referentes ao $4^{\circ}$ trimestre de 2009 justificam que no 4T09, os custos e despesas operacionais montaram $\mathrm{R} \$ 1.743,5$ milhões, crescimento de $15,2 \%$ e 5,5\% em relação ao $4 \mathrm{~T} 08$ e 3T09, respectivamente. Tal elevação foi principalmente ocasionada pelo aumento com despesas de pessoal e do montante dispendido com a compra de energia elétrica para revenda. Salienta-se que tais fatores não foram devidamente captados pelos modelos.

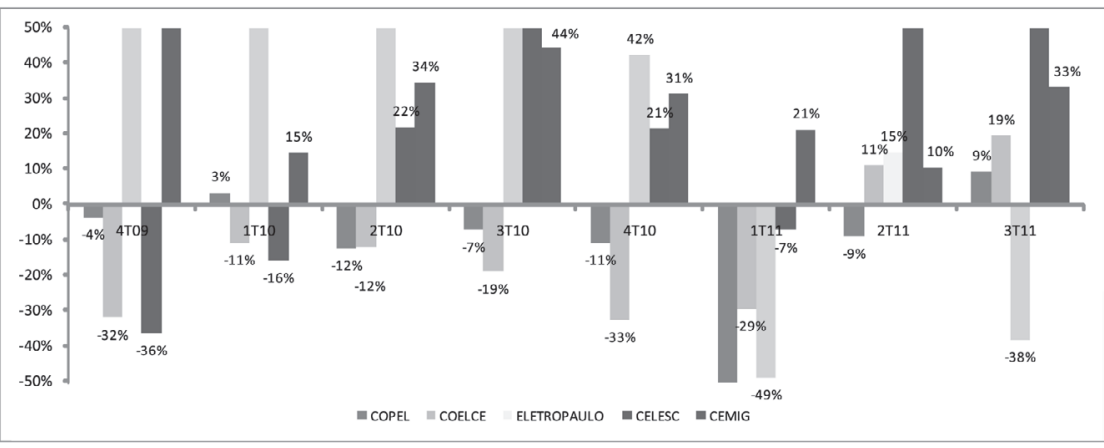

Gráfico 1 - Comparação entre a média das distribuições geradas a partir dos modelos ARIMA e os valores reais (diferença expressa em percentuais dos valores reais)

Fonte: Resultados da pesquisa. 


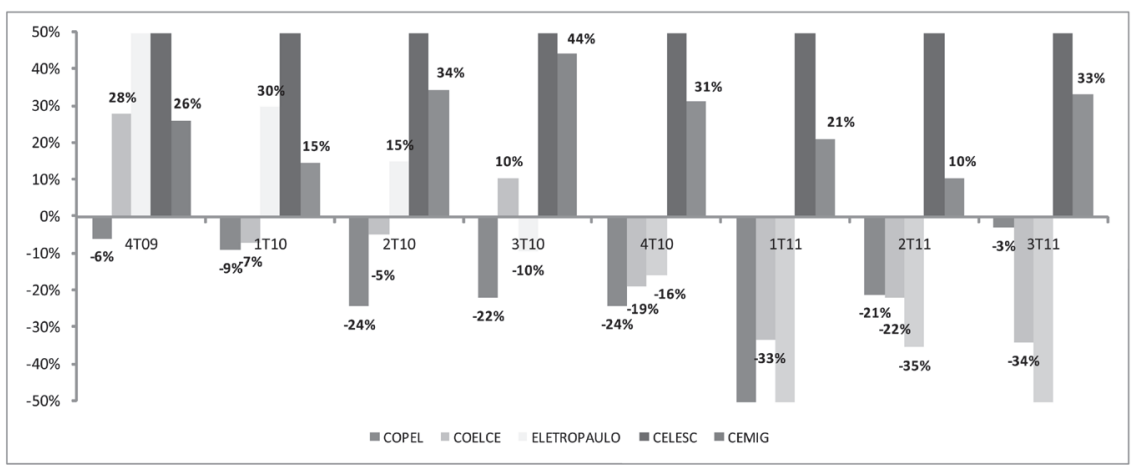

Gráfico 2 - Comparação entre a média das distribuições geradas a partir dos modelos VAR/VECM e os valores reais (diferença expressa em percentuais dos valores reais)

Fonte: Resultados da pesquisa.

Dado o exposto, observa-se a dificuldade encontrada pelas abordagens econométricas utilizadas para captar determinados eventos específicos, tais como: aumentos significativos nas tarifas de compra de energia (que são livremente negociadas pelas geradoras sem nenhuma intervenção da ANEEL), aumento das contingências trabalhistas, decisões de participações acionárias em outras empresas, ampliação da rede de fornecimento, viabilizando a captação de novos consumidores, aumentos em índices de eficiência, entre outros. Tais evidências apontam para a complexidade do ambiente das distribuidoras, que acarretam dificuldades de projeções de longo prazo de resultados financeiros, principalmente dentro do contexto de pequenas amostras.

Através da comparação das abordagens ARIMA e VAR/VECM, aplicadas em uma base de dados compostas por 47 observações, é possível inferir que, apesar da dificuldade de se mapear e de se observar todos os fatores de risco relevantes para as firmas, sejam eles idiossincráticos ou macroeconômicos, a metodologia de vetores autorregressivos tende a apresentar maior acurácia, quando comparada aos modelos autorregressivos integrados de médias móveis, por apresentar menor REQM (Raiz do Erro Quadrado Médio) para três das cinco firmas que integraram a amostra, como demonstrado na Tabela 4: 
Tabela 4 - Comparação da Raiz do Erro Quadrático Médio

\begin{tabular}{|c|c|c|}
\hline \multicolumn{3}{|c|}{ Abordagens de Estimação do CF@R } \\
\hline Empresa & ARIMA & VAR/VECM \\
\hline COPEL & 293.286 & 281.715 \\
\hline COELCE & 53.772 & 50.989 \\
\hline ELETROPAULO & 385.688 & 427.236 \\
\hline CELESC & 86.970 & 367.730 \\
\hline CEMIG & 1.207 .835 & 664.697 \\
\hline
\end{tabular}

Nota: Em cada coluna pode ser visualizada a Raiz do Erro Quadrático Médio, obtida para cada método de estimação. Cada linha sinaliza a empresa de análise.

Fonte: Resultados da pesquisa.

Abeysingue, Balasooriya e Tsui (2000) compararam, empiricamente, via simulação de Monte Carlo, a acurácia da previsão de modelos do tipo ARIMA e de regressão, aplicados ao contexto de pequenas amostras e concluíram que, de fato, em amostras extensas, modelos de regressão com variáveis exógenas tendem a oferecer projeções não significativamente melhores do que os modelos do tipo ARIMA. No entanto, tal afirmação não pode ser aplicada ao contexto de pequenas amostras $(\mathrm{n}<=100)$, nas quais modelos de regressão tendem a apresentar maior precisão preditiva, mesmo em face da necessidade de previsão das variáveis exógenas. Ainda segundo esses autores, os efeitos negativos decorrentes dos erros gerados nas previsões adicionais tendem a ser inferiores aos ganhos de eficiência obtidos durante a estimação dos parâmetros dos modelos multivariados.

Dada sua superioridade em termos de acurácia em relação aos modelos ARIMA, a perda máxima (quando negativo) ou o ganho mínimo (quando positivo) de fluxo de caixa operacional estimado pela abordagem VAR/VECM, bem como a probabilidade associada ao valor nulo, podem ser assim visualizados para um nível de significância de $5 \%$ na Tabela 5: 


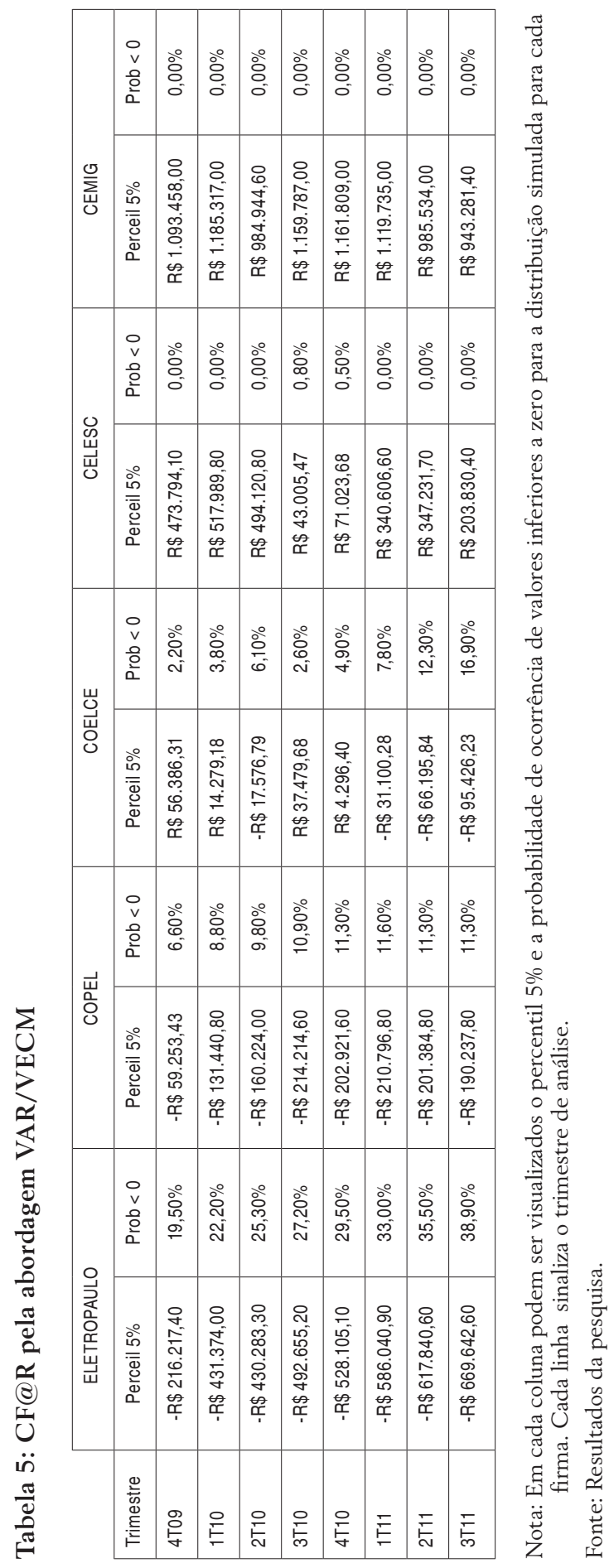


Em geral, a probabilidade de se obter valores inferiores a 0 para a variável fluxo de caixa operacional foi inferior a $20 \%$, exceto para a ELETROPAULO. A CEMIG, por exemplo, apresentou uma distribuição de fluxo de caixa operacional apenas composta por valores positivos, mesmo quando o foco é a cauda extrema esquerda (percentil 5\%). Adicionalmente, foram verificados menores coeficientes de variação para as distribuições simuladas, definidos como a relação entre a dispersão da variável de interesse em relação ao valor médio (expressos na Tabela 6), para a empresa. Salvo a ocorrência de algum evento novo, capaz de gerar um cenário diferente dos esperados, observa-se uma ampla disponibilidade de recursos internos futuros por parte da firma quando comparada às demais, seja para fazer frente aos investimentos programados ou obrigações assumidas. A reduzida oscilação do seu fluxo de caixa operacional também pode contribuir para captação de recursos no mercado, principalmente na forma de emissão de títulos de dívidas, tais como debêntures.

Não obstante seu porte e desempenho histórico, foi verificada uma maior variabilidade para as distribuições da ELETROPAULO, que apresentou, em alguns períodos, probabilidades de ocorrência de valores nulos superiores a 38\% ( $3^{\circ}$ trimestre de 2011).

Tabela 6 - Coeficiente de Variação das Distribuições Obtidas pela Abordagem VAR/VECM

\begin{tabular}{|l|c|c|c|c|c|}
\cline { 2 - 6 } \multicolumn{1}{c|}{ Trimestre } & ELETROPAULO & COPEL & COELCE & CELESC & CEMIG \\
\hline 4T09 & $78,28 \%$ & $67,07 \%$ & $47,97 \%$ & $19,19 \%$ & $25,59 \%$ \\
\hline 1 T10 & $106,15 \%$ & $76,46 \%$ & $59,17 \%$ & $19,36 \%$ & $24,45 \%$ \\
\hline 2T10 & $106,99 \%$ & $81,12 \%$ & $66,17 \%$ & $19,92 \%$ & $25,18 \%$ \\
\hline 3T10 & $121,59 \%$ & $86,13 \%$ & $53,00 \%$ & $51,66 \%$ & $24,28 \%$ \\
\hline 4T10 & $130,41 \%$ & $86,62 \%$ & $61,30 \%$ & $46,59 \%$ & $24,47 \%$ \\
\hline 1T11 & $148,45 \%$ & $88,25 \%$ & $72,37 \%$ & $25,20 \%$ & $25,20 \%$ \\
\hline 2T11 & $165,05 \%$ & $87,39 \%$ & $90,13 \%$ & $24,52 \%$ & $26,27 \%$ \\
\hline 3T11 & $191,93 \%$ & $87,21 \%$ & $110,02 \%$ & $33,48 \%$ & $26,14 \%$ \\
\hline
\end{tabular}

Nota: Em cada coluna pode ser visualizado o coeficiente de variação para as distribuições obtidas para cada firma. Cada linha sinaliza o trimestre de análise.

Fonte: Resultados da pesquisa. 


\section{E. Backtesting}

Um dos métodos propostos por Kuppiec (1995) para avaliação dos resultados de modelos de estimação de valor em risco se pauta no desempenho histórico dos lucros e perdas e baseia-se na utilização da simulação histórica como técnica de validação do Value-at-Risk (V@R). ${ }^{11}$ Para um portfólio qualquer, é possível calcular as modificações diárias em seu valor caso a estrutura de pesos e a composição dos ativos mantenham-se constantes durante um determinado período. Com base na premissa de coeteris paribus, as modificações históricas no valor do portfólio, resultantes apenas das mudanças diárias dos preços de mercado e taxas de juros, poderiam ser usadas para construir um histograma amostral. A partir desse histograma, as estimativas de perdas financeiras associadas a probabilidades de $1 \%$ ou $5 \%$, por exemplo, poderiam ser calculadas. Para adaptar os métodos de backtesting da estimativa de V@R para o CF@R, destaca-se como principal aspecto crítico a ausência de um número significativo de informações reais fora da amostra. Isso porque, enquanto o V@R utiliza informações diárias, o CF@R se pauta normalmente em observações trimestrais, dificultando a estimação da medida de risco e do respectivo backtesting.

A fim de minimizar tal deficiência, o presente estudo propõe a utilização da simulação de Monte Carlo em detrimento da histórica, em virtude da limitação da extensão amostral. Assim, foram geradas 1.000 estimativas para os fatores de risco e para o termo de erro, presentes no modelo VAR/VECM, que viabilizaram o cálculo de distribuições para o primeiro, segundo, terceiro e quarto trimestres de cada ano. Tais resultados, ao serem comparados com as oito estimativas de CF@R fora da amostra, geraram estatísticas referentes à proporção de exceções (proporção de observações simuladas inferiores ao $\mathrm{CF} @ \mathrm{R}$ calculado). Com base no teste de igualdade de proporções, descrito por Triola (2005), avaliou-se a acurácia do fluxo de caixa em risco, para cada um dos oito períodos fora da amostra (do $4^{\circ}$ trimestre de 2009 ao $3^{\circ}$ de 2011). Para averiguar a acurácia geral das estimativas de $\mathrm{CF} @ \mathrm{R}$, foi verificada a igualdade das proporções médias segundo o teste de igualdade de médias para amostras independentes com variâncias desconhecidas, gerando os resultados presentes na Tabela 7:

${ }^{11}$ O Value-at-risk é uma medida de risco bastante utilizada pelas instituições financeiras ao longo da década de 90 e que retorna o quantil associado a um certo percentil de interesse da distribuição de valores de ativos ou carteiras de ativos. 
Tabela 7 - Análise da proporção Média de Exceções em Relação à Medida de CF@R

\begin{tabular}{|l|c|c|c|c|c|}
\cline { 2 - 6 } \multicolumn{1}{c|}{} & Média da Proporção de Exceções (pM) & \multicolumn{4}{c|}{$\mathrm{p}$-Value } \\
\hline Empresa & & $\mathrm{H} 1 \mathrm{pM}<0,05$ & $\mathrm{H} 1 \mathrm{pM} \neq 0,05$ & $\mathrm{H} 1: \mathrm{pM}>0,05$ & Status \\
\hline CELESC & $0.1146 \%$ & 0.9583 & 0.0833 & 0.0417 & $\mathrm{pM}>5 \%$ \\
\hline COELCE & $0.2423 \%$ & 0.9984 & 0.0033 & 0.0016 & $\mathrm{pM}>5 \%$ \\
\hline COPEL & $0.0581 \%$ & 0.8916 & 0.2186 & 0.1084 & $\mathrm{pM}=5 \%$ \\
\hline ELETROPAULO & $0.0487 \%$ & 0.4697 & 0.9393 & 0.5303 & $\mathrm{pM}=5 \%$ \\
\hline CEMIG & $0.0162 \%$ & 0.0000 & 0.0000 & 1.000 & $\mathrm{pM}<5 \%$ \\
\hline
\end{tabular}

Nota: Na primeira coluna pode ser visualizada a média da proporção de exceções e nas subsequentes o p-value para cada teste de hipótese aplicado.

Fonte: Resultado da pesquisa.

Segundo as estatísticas obtidas, é possível inferir, a um nível de significância de 5\%, que as medidas de CF@R estimadas para os oito trimestres de análise foram satisfatórias para COPEL ELETROPAULO, mas tenderam a superestimar o risco para a CEMIG e a subestimá-lo para CELESC e COELCE. Acredita-se que existam variáveis que impactaram a volatilidade do fluxo de caixa nesses trimestres para as duas empresas e que não foram quantificadas no respectivo estudo, bem como fatores considerados outliers que interferiram no nível de acurácia da medida de CF@R. A suscetibilidade dos resultados operacionais ao comportamento dos consumidores livres é destacado tanto pelo departamento de relações de investidores da COELCE e da CELESC como um fator de risco crucial para as distribuidoras.

Após apurar o percentual de participação dos consumidores livres sobre a demanda total das distribuidoras durante o período do $4^{\circ}$ trimestre de 2009 ao $3^{\circ}$ trimestre de 2011, observa-se que o patamar de exposição da COELCE aos mesmos gira em torno de $9 \%$ em 2010 , chegando a $13 \%$ no $3^{\circ}$ trimestre de 2011 , enquanto, no caso da CELESC, este índice supera os 20\% no $3^{\circ}$ trimestre de 2011. Já para a CEMIG este patamar assume a ordem de $30 \%$ no $3^{\circ}$ trimestre de 2011. Logo, caso outras concessionárias de maior porte possam oferecer preços mais competitivos para o fornecimento de energia, o nível de queda ou crescimento inferior dos resultados operacionais da segunda distribuidora será mais significativo. A não consideração dessa variável de risco pode ter contribuído para as falhas na estimação do CF@R para as três firmas. 


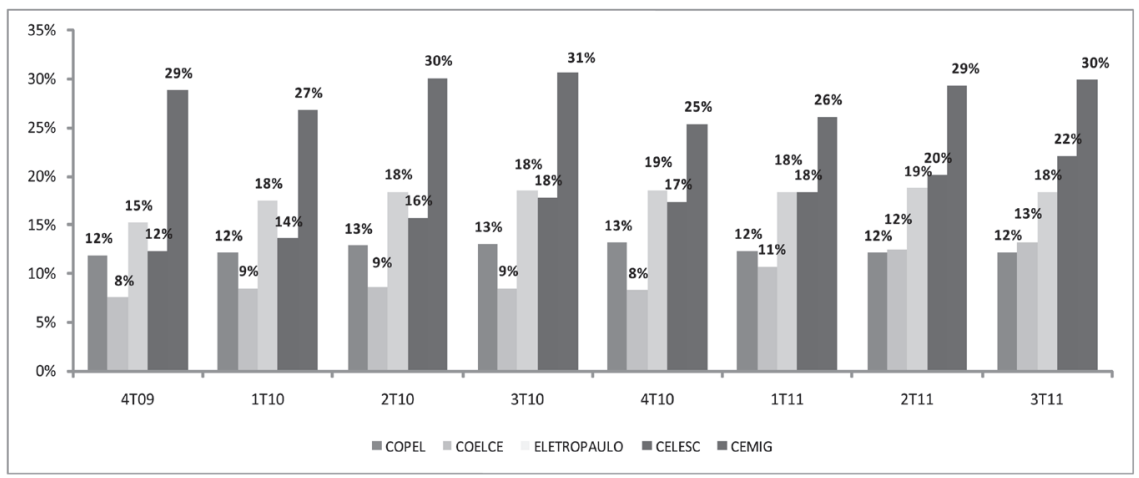

Gráfico 3 - Percentual de participação dos consumidores livres sobre a demanda agregada

Fonte: Elaborado pelos autores.

\section{F. Stress Testing}

No contexto de instituições não financeiras, Damodaran (2004) destaca que a análise dos cenários extremos pode oferecer bons insights visto que, no ambiente corporativo, a consideração dos piores cenários pode representar um ponto de partida para avaliação dos riscos associados a situações de baixa liquidez, que comprometem a capacidade da firma em arcar com possíveis financiamentos e manter ou criar novos projetos de investimento. Em geral, os testes de stress são relevantes na avaliação do efeito de grandes oscilações nas variáveis-chave, o que equivale à retirada de alguns pontos do extremo da distribuição que representem, de fato, informações úteis (Jorion, 1997).

Salienta-se que foram gerados cenários extremos pautados na cauda inferior (0 a 5\%) das distribuições dos fatores de risco, para a maioria das variáveis explicativas, a saber: Produto Interno Bruto (PIB); demanda residencial (DEMANDRESID); demanda agregada (DEMANDAGREG); energia comprada (ENERGCOMP) e tarifa média de venda de energia (TMV). As demais variáveis, representadas pelas tarifas médias de compra de energia (TMC), foram simuladas segundo valores presentes na cauda superior da distribuição (95 a 100\%), visto que variações positivas dessas variáveis (ou seja, aumento do desemprego e da tarifa de compra do insumo energia) tendem a impactar negativamente o fluxo de caixa das empresas dis- 
tribuidoras de energia elétrica. Após terem sido realizados os testes de stress, foi verificado que os valores projetados de fluxo de caixa operacional para todas as firmas permaneceram positivos, apesar de se observar reduções bruscas quando comparados àqueles obtidos sob condições normais. Dessa forma, verifica-se que, mesmo em cenários de elevação de custos e despesas operacionais, existem recursos disponíveis para arcar com um montante referente às decisões de investimentos das firmas, quando se avalia como ponto de referência o valor médio das distribuições de stress. No entanto, como valores presentes em intervalos da cauda extrema são passíveis de ocorrer (mesmo com probabilidade pequena) a medida de CF@R não deve ser negligenciada, sendo um bom indicador da situação de liquidez da firma dada uma perspectiva pessimista, tal como um novo racionamento, por exemplo, marcado por uma queda brusca na demanda total. A consideração de tais possibilidades permite ao gestor fomentar medidas contingenciais ou reavaliar políticas de investimentos em circunstâncias nas quais tais eventos possam ser eminentes.

Quando se compara a média da distribuição antes e após o stress test, constata-se que, para algumas firmas, foram verificadas alterações bruscas nos valores projetados para a variável fluxo de caixa operacional, devido aos maiores coeficientes presentes nos modelos estimados, gerando uma exposição maior a oscilações nos fatores de risco, como demonstrado pela Tabela 8:

Tabela 8 - Variação Percentual da Média da Distribuição do Fluxo de Caixa em virtude do StressTest

\begin{tabular}{|c|c|c|c|c|c|}
\hline Trimestre & ELETROPAULO & COPEL & COELCE & CELESC & CEMIG \\
\hline 4 TO9 & $*$ & $-25,642 \%$ & $*$ & $*$ & $-17,404 \%$ \\
\hline $1 \mathrm{~T} 10$ & $-55,948 \%$ & $-29,291 \%$ & $-13,667 \%$ & $-12,484 \%$ & $-17,350 \%$ \\
\hline $2 \mathrm{~T} 10$ & $-55,855 \%$ & $-30,798 \%$ & $-11,211 \%$ & $-12,901 \%$ & $-17,616 \%$ \\
\hline $3 \mathrm{~T} 10$ & $-63,941 \%$ & $-32,576 \%$ & $-14,071 \%$ & $-33,502 \%$ & $-16,867 \%$ \\
\hline $4 \mathrm{~T} 10$ & $-69,052 \%$ & $-32,938 \%$ & $-16,057 \%$ & $-30,472 \%$ & $-16,525 \%$ \\
\hline $1 \mathrm{~T} 11$ & $-78,168 \%$ & $-33,547 \%$ & $-19,199 \%$ & $-16,272 \%$ & $-18,258 \%$ \\
\hline $2 \mathrm{~T} 11$ & $-88,032 \%$ & $-33,282 \%$ & $-23,443 \%$ & $-16,005 \%$ & $-17,300 \%$ \\
\hline $3 \mathrm{~T} 11$ & $-102,049 \%$ & $-33,067 \%$ & $-29,156 \%$ & $-54,222 \%$ & $-17,543 \%$ \\
\hline
\end{tabular}

Nota: Em cada coluna encontram-se expressas as variações percentuais da média da distribuição do fluxo de caixa quando se comparam os valores encontrados antes e após os cenários de stress. Em cada linha estão representados os trimestres de análise.

Fonte: Resultados da pesquisa. 


\section{Considerações Finais}

Este estudo propôs uma ferramenta para análise da liquidez aplicada ao contexto de instituições não financeiras por meio do cômputo do fluxo de caixa em risco, $\mathrm{CF} @ \mathrm{R}$, para algumas das principais distribuidoras de energia do setor elétrico brasileiro. Para tal, compararam-se duas abordagens econométricas, a saber: os modelos ARIMA e de vetores autorregressivos (VAR/VECM). Foram analisadas, portanto, duas formas de estimação do CF@R: a primeira embasada apenas nos comportamentos passados da variável de interesse e do seu termo de erro, como apontado por Stein et al. (2001), e a segunda composta por uma parcela condicionada e outra não condicionada aos fatores de risco sistêmicos e idiossincráticos (modelagem via vetores autorregressivos, conjugada à simulação dos termos de erro) como discutido no RiskMetrics (1999) e em Andrén, Jankesgard e Oxlheim (2005).

Mesmo em face da dificuldade de levantamento da base histórica dos fatores de risco, seja pela sua não observação, dada a não divulgação recorrente nos relatórios trimestrais, seja pela dificuldade de quantificação, o modelo de média condicionada a variáveis exógenas superou o modelo autorregressivo em termos de acurácia preditiva na maior parte da amostra, por apresentar menor estatística de erro fora da amostra, para três das cinco distribuidoras analisadas. Tal resultado é discutido em Abeysingue, Balasooriya e Tsui (2000), ao apontarem as dificuldades associadas à obtenção de estimativas eficientes para os modelos do tipo ARIMA, dentro do contexto de pequenas amostras.

Além de subsidiar o tomador de decisão com informações sobre valores extremos (ganhos mínimos ou perdas máximas, associados ao respectivo nível de significância), a abordagem apresentada fornece informações capazes de norteá-lo durante o planejamento de investimentos, ou análise da capacidade da firma em arcar com encargos financeiros decorrentes da captação de novas dívidas. Ao utilizar modelos de projeção para a variável de interesse pautados na média (visto que as distribuições simuladas se assemelham à normal), buscou-se sumarizar 10.000 cenários prováveis em um único valor. Tais estimativas também poderiam subsidiar análises de valuation ou ampliar o nível de transparência para com o investidor externo, principalmente em momentos de emissão de debêntures, por exemplo. 
Não obstante, salienta-se que o método exposto não se limita apenas à verificação do nível de liquidez, pois, ao mapear os fatores de risco que interferem na variável em estudo, geram-se índices de sensibilidade (representado pelos coeficientes dos modelos VAR/VECM) que podem subsidiar decisões de hedge.

O ponto mais relevante a ser destacado como contribuição do artigo, entretanto, diz respeito à adoção de procedimentos de backtesting e geração de análises do tipo stress test, até então não realizados em nenhum outro trabalho da área no Brasil, consistindo em importantes instrumentos de análise. Esse ferramental pode auxiliar o gestor na elaboração de planos contingenciais e na quantificação do risco adicional em cenários extremos, tais como racionamento, nos quais são esperadas quedas bruscas na variável demanda.

Como principal limitação do estudo, destaca-se a dificuldade de transposição da abordagem de backtesting aplicada à metodologia V@R para a análise do CF@R, em virtude do número de observações disponíveis. Dada a ausência de dados reais, foram utilizadas simulações que, ao reproduzir o comportamento passado da variável, não captam mudanças decorrentes da ocorrência de novos eventos. Outro ponto relevante diz respeito à aplicação dos testes de proporção no contexto de pequenas amostras, que implica a baixa capacidade de detecção de problemas de subestimação ou superestimação do $\mathrm{CF} @ \mathrm{R}$, visto que o intervalo de confiança passa a ser mais amplo, dificultando a não aceitação do modelo caso o mesmo seja falho.

No que tange aos resultados do backtesting, constatou-se que as estimativas de CF@R foram em média superestimadas para a COELCE e subestimadas para a CELESC, em virtude de variáveis relevantes não observáveis e presença de outliers.

Ressaltam-se, por fim, problemas de data snooping, que tendem a ser agravados no contexto de pequenas amostras. White (2000) descreve tais problemas como sendo resultado da utilização de um conjunto de dados de forma sucessiva a fim de realizar inferências ou seleção de modelos estatísticos. Quando tal processo ocorre, sempre existe a possibilidade de que a ocorrência de resultados considerados satisfatórios decorram do acaso, e não em virtude da correta especificação do modelo. Logo, quando um "bom" modelo é obtido após uma extensiva pesquisa de especificações, sempre existe o perigo de 
que o desempenho apresentado não seja necessariamente inerente à habilidade de projeção, mas sim a uma mera coincidência, que pode inclusive ser consequência de correlações espúrias. Segundo o autor, esse tipo de problema é praticamente inevitável quando se trabalha com séries temporais, caso no qual procura-se descrever um processo gerador de dados a partir de um número limitado de informações.

Como possibilidade de estudos futuros, sugere-se a estimação de modelos que sejam mais robustos para pequenas amostras, via estudo da aplicação da técnica de bootstrapping ao contexto de séries temporais, na qual se simularia o termo de erro, dada a sua não correlação temporal, em detrimento da variável dependente $\mathrm{x}_{\mathrm{t}}$ como apontado nos trabalhos de Poi (2004). Tal técnica poderia viabilizar a aplicação de modelos individuais, em detrimento da análise em painel, para tratamento de problemas de insuficiência de dados. Esse procedimento seria fundamental para apuração de modelos mais eficientes que captem as relações complexas presentes no setor de distribuição de energia elétrica, bem como para propiciar maior acurácia nas previsões de longo prazo.

Outro ponto a ser destacado como possibilidade de estudos futuros diz respeito à estimação completa do modelo MUST (Modeling Uncertainty Strategy) proposto por Andrén, Jankesgard e Oxlheim (2005), que trata as variáveis independentes como um desvio em relação ao seu valor médio estimado.

\section{Referências}

ABEYSINGHE, T.; BALASOORIYA, U.; TSUI, A. Small-sample Forecastin: Regression or ARIMA Models? Disponível em http://courses.nus.edu.sg/course/ecstabey/Tilak\%20Bala\%20Albert-2. pdf. Acesso em 10/05/2012.

AGÊNCIA NACIONAL DE ENERGIA ELÉTRICA, O mercado de distribuição de energia. 2008. Disponível em http:// www.aneel.gov.br. Acesso em: 08/09/2009.

ANDRÉN, N.; JANKESGARD, H.; OXLHEIM, Lars. Exposure-based cash flow at risk under macroeconomic uncertainty. Journal of Applied Corporate Finance, 17: 76-86. 2005.

BOX, G.; JENKINS, G. Time series analysis: Forecasting and control. Holden-Day, San Francisco, 3. ed., 1970.592 p.

BROOKS, C. (2008). Introductory econometrics for finance. Cambridge University Press, New York, 1. ed., $728 \mathrm{p}$.

CHRISTOFFERSEN, P. (2003). Elements of financial risk management. Academic Press, California, 1. ed., $214 \mathrm{p}$. 
DAMODARAN, A (2004). Finanças corporativas: teoria e prática. Bookman, Porto Alegre, 2. ed., 796 p.

DRAPER, N. \& Smith, H. (1998). Applied regression analysis. Wiley, New York, 1. ed., 736 p.

ENDERS, W. (2004). Applied econometric time series. John Wiley \& Sons, New Jersey, 2. ed., 480 p.

HAMILTON, J. (1994). Times series analysis. Princeton University Press, New Jersey, 1. ed., 800 p.

HEIJ, C.; BOER, P.; FRANSES, P.; KLOEK, T.; DIJK, H. Econometric methods with applications in business and economics. Oxford University Press, New York, 1. ed., 2004. 816 p.

INSTITUTO BRASILEIRO DE GEOGRAFIA E ESTATÍSTICA. Produção Física-Brasil Indicadores Especiais por Intensidade do Gasto com Energia Elétrica. Disponível em http://www.ibge.gov. $\mathrm{br} /$ home/estatistica/indicadores/industria/pimpfbrenergia_nova/defaulttabenergia.shtm. Acesso em: 07/09/2009. 2009.

IUDÍCIBUS, S.; MARTINS, E.; GELBCKE, E. Manual de contabilidade das sociedades por ações. Atlas, São Paulo, 7. ed., 2007. 672 p.

JOHNSTON, J.; DINARDO, J. Métodos econométricos. Mcgraw-Hill, São Paulo, 4. ed., 2001. 573 p.

JORION, P. Value at risk: the new benchmark for controlling market risk. Mcgraw-Hill, Chicago, 2. ed., 1997. 544 p.

KIMBALL, R. Failures in risk management. 2000. Disponível em http://www.bos.frb.org/economic/ neer/neer2000/neer100a.pdf. Acesso em 28/02/2012.

KUPPIEC, P. Techniques for verifying the accuracy of risk measurement models. FEDS Paper Number: 95-24, 1995. Disponível em http://ssrn.com/abstract=6697. Acesso em: 28/02/2012.

LA ROCQUE, E. LOWENKRON, A. Métricas e particularidades da gestão de risco em corporações. 2004. Disponível em http://m.1asphost.com/cenarios/gestaoriscos/setorfinanceiro/MetricasRiskControl_Particularidades.pdf.Acesso em 28/02/2012.

LA ROCQUE, E.; LOWENKRON, A.; JENSEN, J. Cenários probabilísticos: conjugando análises de riscos e projeções macroeconômicas. 2003. Disponível em http://m.1asphost.com/cenarios/gestaoris$\cos$ /setorfinanceiro/AnaliseRiscosProjecoesMacroeconomicas.pdf. Acesso em 28/02/2012.

MADDALA, G. Introdução à econometria. Livros Técnicos e Científicos Editora, Rio de Janeiro, 3. ed., 2003. 368 p.

MAKRIDAKIS, S.; WHEELWRIGHT, S.; HYNDMAN, R. Forecasting: methods and applications. John Wiley \& Sons, New York, 3. ed., 1998. 656 p.

MONTGOMERY, D.; JOHNSON, L. Forecasting and time series analysis. McGraw Hill, New York, 1. ed., 1976. 288 p.

MUN, J. Modeling risk: applying Monte Carlo simulation, real options analysis, forecasting, and optimization techniques. Wiley Finance, New Jersey, Kindle Edition, 2006. 624 p.

NAWROCKI, D. A Brief History of Downside Risk Measures. The Journal of Investing, 8:9-25, 1999.

NETO, J. Fluxo de caixa em risco em empresas não financeiras. Revista de Administração (São Paulo), 42:239-248, 2007.

POI, B. Some bootstrapping techniques. The Stata Journal, 4:312-328, 2004.

PEROBELLI, F. Um modelo para gerenciamento de riscos em instituições não financeiras: aplicação ao setor de distribuição de energia elétrica no Brasil. Faculdade de Economia, Administração e Contabilidade, Universidade de São Paulo, São Paulo. Tese de Doutorado. 2004.

PEROBELLI, F.; JANUZZI, F.; BERBERT, L.; MEDEIROS, D. Fluxo de Caixa em Risco: Diferentes Métodos de Estimação Testados no Setor Siderúrgico Brasileiro. Revista Brasileira de Finanças, 5:165-204. 2007.

RISKCONTROL. Gestão de riscos de mercado em ambiente corporativo: questões Práticas e Diferenças com Relação a Instituições Financeiras. 2002. Disponível em http://www.listaderiscos.com.br. Acesso em: 17/01/2009. 
RISKMETRICS GROUP. CorporateMetrics technical document. 1999. Disponível em http://www. riskmetrics.com. Acesso em: 19/01/2009.

RISKMETRICS GROUP. Long run technical document. 1999.Disponível em http://www.riskmetrics. com. Acesso em: 19/01/2009.

ROCHA, A. Fluxo de caixa em risco: uma nova abordagem para o setor de distribuição de energia elétrica. Departamento de Engenharia Elétrica, Pontifícia Universidade Católica do Rio de Janeiro, Rio de Janeiro. Tese de Mestrado. 2008.

ROSS, S. Simulation. Academic Press, California, 4. ed., 2002. 312 p.

RUBSTEIN, R. Simulation and the Monte Carlo method. Jonh Wiley \& Sons, Canada, 1. ed., 1981.304 p.

SIMS, C. Macroeconomics and Reality. Econometrica, 48:1-48. 1980.

SOBOL, I. A primer for the Monte Carlo method. CRC Press LLC, Florida, 1. ed., 1994. 128 p.

STEIN, J.; USHER, S.; LAGATTUTA, D.; YOUNGEN, J. A comparable approach to measuring cashflow-at-risk for non-financial firms. Journal of Applied Corporate Finance, 13:8-17. 2001.

WHITE, H. Maximum likelihood estimation of misspecified models. Econometrica, 50:1-25. 1982.

WHITE, H. A Reality Check for Data Snooping. Econometrica, 68:1097-1126. 2000.

WINSTOWN, W. Operations research: applications and algorithms. Duxbury Press, 3. ed., 2004. 1392 p. 